Review

\title{
The Effects of High Concentrations of Vitamin C on Cancer Cells
}

\section{Seyeon Park}

Department of Applied Chemistry, Dongduk Women's University, 23-1 Wolgok-dong, Sungbuk-ku, Seoul 136-714, Korea; E-Mail: sypark21@dongduk.ac.kr or seypark21@hotmail.com; Tel.: +82-2-940-4514; Fax: +82-2-940-4193

Received: 8 July 2013; in revised form: 22 August 2013 / Accepted: 23 August 2013 /

Published: 9 September 2013

\begin{abstract}
The effect of high doses of vitamin $\mathrm{C}$ for the treatment of cancer has been controversial. Our previous studies, and studies by others, have reported that vitamin $\mathrm{C}$ at concentrations of $0.25-1.0 \mathrm{mM}$ induced a dose- and time-dependent inhibition of proliferation in acute myeloid leukemia (AML) cell lines and in leukemic cells from peripheral blood specimens obtained from patients with AML. Treatment of cells with high doses of vitamin $\mathrm{C}$ resulted in an immediate increase in intracellular total glutathione content and glutathione-S transferase activity that was accompanied by the uptake of cysteine. These results suggest a new role for high concentrations of vitamin $\mathrm{C}$ in modulation of intracellular sulfur containing compounds, such as glutathione and cysteine. This review, discussing biochemical pharmacologic studies, including pharmacogenomic and pharmacoproteomic studies, presents the different pharmacological effects of vitamin $\mathrm{C}$ currently under investigation.
\end{abstract}

Keywords: high concentrations of vitamin C; pharmacogenomics; pharmacoproteomics

\section{Introduction}

There is increasing evidence that vitamin $\mathrm{C}$ (ascorbate) is selectively toxic to some types of tumor cells, functioning as a pro-oxidant [1-3]. Vitamin $\mathrm{C}$ at concentrations of $10 \mathrm{nM}-1 \mathrm{mM}$ induced apoptosis in neuroblastoma and melanoma cells [4] and was shown to be an important modulator for the growth of mouse myeloma cells in an in vitro colony assay [5]. Studies have established that the growth of leukemic progenitor cells from patients with acute myeloid leukemia (AML) and myelodysplastic syndromes (MDS) can be significantly modulated by vitamin $C$ [6,7]. Intravenous 
(i.v.) administration of sodium 5,6-benzylidene-l-ascorbate (SBA) to inoperable cancer patients induced a significant reduction in tumor volume without any adverse side effects [8]. Furthermore, recent clinical studies have reported that manipulation of vitamin $\mathrm{C}$ levels in vivo can result in clinical benefit for patients with AML and solid tumors [9].

Recent pharmacokinetic studies reported that $10 \mathrm{~g}$ of ascorbate given by i.v. produced plasma concentrations of nearly $6 \mathrm{mM}$, which were 25 -fold higher than concentrations resulting from the same oral dose [10-12]. Depending on the dose, as much as a 70-fold difference in plasma concentration was found between oral and i.v. administration [13]. Complementary and alternative medicine practitioners worldwide currently use ascorbate i.v. in patients, in part because there are no apparent harmful effects [14-16]. Physiological concentration of vitamin $\mathrm{C}$ is under $0.1 \mathrm{mM}$, while plasma vitamin $\mathrm{C}$ concentrations that cause toxicity to cancer cells in vitro $(1 \mathrm{mM}-10 \mathrm{mM}$, depending on cell lines) can be achieved clinically by intravenous administration, which means a high dose of vitamin $\mathrm{C}$.

In this review, in vitro and in vivo studies are summarized, showing that ascorbate killed cancer cells (Table 1). In addition, the mechanisms and physiologic relevance under investigation are also described. The results suggest that doses of vitamin $C$ induce oxidative stress in cancer cells. Our previous results indicated that treatment of malignant lymphocytic cell lines with vitamin $\mathrm{C}(0.25-1 \mathrm{mM})$ for $24 \mathrm{~h}$ led to a marked dose-dependent decrease of cell proliferation [17]. The responsive cell lines were human myeloid leukemia cell line HL-60, retinoic acid (RA)-sensitive acute promyelocytic leukemia (APL) cell line NB4 and RA-resistant APL cell line NB4-R1. Different types of leukemia cells, such as K562 (chronic myelogenous leukemia cell line) [17] and KG1 (myeloblast cell line) [18], were also responsive to vitamin C. A similar result was obtained with cells containing over $90 \%$ of blasts from patients with AML. In these cell lines, induction of apoptosis by vitamin $\mathrm{C}$ demonstrated a dose-dependent effect. In addition, vitamin $\mathrm{C}$ weakly induced apoptosis in ovarian cell lines, including SK-OV-3, OVCAR-3 and 2774 [17]. For many of the cancer cell lines, ascorbate concentrations caused a $50 \%$ decrease in cell survival. The half maximal concentration $\left(\mathrm{IC}_{50}\right)$ values were less than $5 \mathrm{mM}$, and all tested normal cells were insensitive to $20 \mathrm{mM}$ ascorbate [13].

Table 1. Effects of vitamin $C$ treatment on cell survival $[13,17,18]$.

\begin{tabular}{cc}
\hline Cell Line & IC $_{\mathbf{5 0}}(\mathbf{m M})$ \\
\hline HL-60 & $0.33 \pm 0.18^{*}$ \\
NB4 & $0.76 \pm 0.14^{*}$ \\
NB4-R1 & $0.45 \pm 0.24 *$ \\
NB4-R2 & $0.75 \pm 0.3 *$ \\
KG1 & $0.79 \pm 0.22 *$ \\
K562 & $0.5 \pm 0.11 *$ \\
U937 & $0.3 \pm 0.16^{*}$ \\
Normal Bone Marrow & $1 \pm 0.3 *$ \\
Patient with AML & $0.84 \pm 0.16^{*}$ \\
OVCAR & $>10 *$ \\
SK-OV3 & $>10 *$ \\
JLP119 & $<1$ \\
\hline
\end{tabular}


Table 1. Cont.

\begin{tabular}{cc}
\hline MCF7 & 2 \\
MB231 & 7 \\
Hs587T & 20 \\
KLN205 & $<1$ \\
RAG & $<2$ \\
CT26 & 4 \\
B16 & 7 \\
LL/2 & 11 \\
Hs587Bst & $>20$ \\
CCD34SK & $>20$ \\
Human normal lymphocyte & $>20$ \\
Human normal monocyte & $>20$ \\
\hline
\end{tabular}

The $\mathrm{IC}_{50}$ values are means \pm standard deviations from triplicate experiments. HL-60, human myeloid leukemia; NB4, NB4-R1, NB4-R2, human acute promyelocytic leukemia (APL); KG1, human myeloblast; K562, human chronic myelogenous leukemia; U937, human histiocytic lymphoma; OVCAR, SK-OV3, ovarian cancer; JLP119, human lymphoma; MCF7, MB231, Hs587t, human breast cancer; KLN205, mouse lung cancer; RAG, mouse kidney cancer; CT26, mouse colon cancer; B16, mouse melanoma; LL/2, mouse lung cancer; Hs587Bst, human normal breast cells; CCD34SK, human normal fibroblast cells. * $\mathrm{IC}_{50}$ value was determined using $\mathrm{H}^{3}$ incorporation proliferation assay for $24 \mathrm{~h}$.

\section{Molecular Mechanisms Induced by Vitamin C}

In our previous study, vitamin $\mathrm{C}$ at concentrations of $0.25-2.0 \mathrm{mM}$ significantly induced apoptosis in AML cell lines. Vitamin $\mathrm{C}$ induced oxidation of glutathione (GSH) to its oxidized form (GSSG). As a result, $\mathrm{H}_{2} \mathrm{O}_{2}$ accumulated in a concentration-dependent manner, in parallel with the induction of apoptosis. The direct role of $\mathrm{H}_{2} \mathrm{O}_{2}$ in the induction of apoptosis in AML cells was demonstrated by the finding that catalase could completely abrogate vitamin C-induced apoptosis [17].

A 30-min incubation of NB4 cells with $0-10 \mathrm{mM}$ vitamin $\mathrm{C}$ resulted in its uptake in a concentration-dependent manner [17,19]. In accordance with its proposed pro-oxidant activity, vitamin $\mathrm{C}$ treatment reduced the GSH/GSSG ratio, which correlated with increased intracellular $\mathrm{H}_{2} \mathrm{O}_{2}$ in the NB4 cell line. Levine et al. suggested that the effect was due only to extracellular and not intracellular ascorbate, and that ascorbate-mediated cell death was probably due to protein-dependent extracellular $\mathrm{H}_{2} \mathrm{O}_{2}$ generation, via ascorbate radical formation from ascorbate as the electron donor [13].

Although $\mathrm{H}_{2} \mathrm{O}_{2}$ induced by ascorbate was first generated extracellularly, it is possible that it could diffuse across the plasma membrane into the intracellular space. Although studies in yeast and bacteria have shown that diffusion of $\mathrm{H}_{2} \mathrm{O}_{2}$ across membranes is limited, some reports have suggested that selected aquaporin homologues from plants and mammals can channel $\mathrm{H}_{2} \mathrm{O}_{2}$ across these membranes [20-25]. The susceptibility of cancer cells to ascorbate treatment might therefore be related to the permeability of hydrogen peroxide.

In our studies, vitamin $\mathrm{C}$ dramatically increased intracellular GSH oxidation and reactive oxygen species (ROS) levels within $3 \mathrm{~h}$ in a concentration-dependent manner. However, this GSH oxidation and the ROS accumulation did not last for a long period of time. After $3 \mathrm{~h}$, the increase in GSH has been observed and hypothesized to be a defense mechanism [18]. No additional ROS accumulation 
resulted from the change in GSH. However, based upon our studies, the dramatic changes of intracellular oxidation state within $3 \mathrm{~h}$ seem to be enough to induce intracellular signaling. The studies showed that treatment with $1 \mathrm{mM}$ vitamin $\mathrm{C}$ for only 30-60 min, followed by removal when replacing media, could induce apoptosis in both HL-60 and NB4 cells. This observation is consistent with initiation of apoptosis, resulting from generation of $\mathrm{H}_{2} \mathrm{O}_{2}$ after treatment with ascorbate. However, treatment with $\mathrm{As}_{2} \mathrm{O}_{3}$ resulted in less ROS accumulation than with vitamin $\mathrm{C}$, and it was not in a concentration-dependent manner. However, ROS accumulation increased up to $24 \mathrm{~h}$, with a long-lasting effect. Treatment with vitamin $\mathrm{C}$ combined with $\mathrm{As}_{2} \mathrm{O}_{3}$ increased ROS accumulation, as well as sustained the effect for up to $24 \mathrm{~h}$. These results are consistent with cellular data showing that apoptosis induced by $\mathrm{As}_{2} \mathrm{O}_{3}$ is evident even at three days [26,27].

\section{Proteomics Studies}

Proteomics provides important qualitative information on post-translational modifications to proteins and quantitative data on protein expression in response to a particular stimulus. This information is particularly important when it provides data on early cellular events, such as the stimulus and signaling cascades triggered independently of protein neosynthesis. In accordance with its proposed pro-oxidant activity, vitamin C-mediated reduction in the GSH/GSSG ratio correlated with an intracellular $\mathrm{H}_{2} \mathrm{O}_{2}$ increase in the NB4 cell line [17,19]. This type of change in regional oxidation state could cause changes in the cellular milieu that could result in changes in protein structure. This is especially true of the oxidation state of cysteine sulfur, which is important for determining the tertiary structure of proteins. The immediate effects of cell stimuli are associated with protein post-translational modifications, such as phosphorylation, glutathionylation and cysteine oxidation. To study these early modifications, NB4 human leukemia cells were treated with $0.5 \mathrm{mM}$ vitamin $\mathrm{C}$ and then analyzed by two-dimensional analysis. Approximately 240 different spots that were focused in a $\mathrm{pH}$ range of 4-7 were detected per sample.

After exposing cells to vitamin $C$, we observed one new spot, three intensified spots and five attenuated spots [19]. Each of these spots were excised, digested with trypsin and analyzed by matrix-assisted laser desorption/ionization-time of flight (MALDI-TOF). Peptide mass fingerprint analysis and non-redundant sequence database matching allowed the unambiguous identification of all of the analyzed species [19]. An important protein identified from the proteomic analysis was a thiol/disulfide exchange catalyst, protein disulfide isomerase (PDI), which was a marker of the effect of vitamin C on NB4 cells [19]. PDI belongs to the superfamily of thiol/disulfide exchange catalysts, which act as protein-thiol-oxidoreductase enzymes, sharing sequence homology with thioredoxin [28]. PDI is composed of four domains, which have similarities with thioredoxin folds (i.e., a-b-b'-a') [29]. In our study [19], the intensity of the spot corresponding to the PDI b subunit was decreased in vitamin C-treated cells as compared with control cells. These results demonstrated that thiol/disulfide exchange proteins are regulated in NB4 cells after vitamin C exposure. This is consistent with our study showing that intracellular GSH/GSSG exchange occurs shortly after vitamin C exposure [17].

When we measured cysteine uptake in leukemia cell lines exposed to vitamin $\mathrm{C}$ by using ${ }^{35}$ S-labeled-L-Cys in the media, the time-dependent rate of cysteine uptake in the cell culture increased significantly. The rate of uptake, determined under conditions without vitamin $\mathrm{C}$, was very low. The 
glutathione synthesis inhibitor, buthionine sulfoximine, potently inhibited this increase, suggesting that incorporation of cysteine that corresponded to the amount of increased glutathione was mediated by glutathione synthesis. Overall, our results indicated that vitamin C-induced glutathione synthesis was accompanied by intracellular cysteine uptake.

Glutathione-S transferases (GSTs) are enzymes that catalyze the conjugation of electrophilic substitution to $\mathrm{GSH}$, which protects cells by removing reactive oxygen species and regenerating $S$-thiolated proteins [30]. Intracellular total GSH levels in AML cells incubated with vitamin C peaked around $3 \mathrm{~h}$, then declined, while the increase in incorporated $\left[{ }^{35} \mathrm{~S}\right]$-L-Cys peaked at $3 \mathrm{~h}$ and remained high. These results showed that $\left[{ }^{35} \mathrm{~S}\right]$-L-Cys transported into cells through cysteine uptake was incorporated and transferred intracellularly, strongly suggesting that the sulfhydryl transfer system is affected by vitamin $\mathrm{C}[30]$.

We therefore hypothesize that the biochemical pathway leading to thiol/disulfide redox regulation could be activated by vitamin $\mathrm{C}$. Interestingly, of the proteins whose expressions changed by vitamin $\mathrm{C}$ treatment, immunoglobulin heavy chain binding protein (BiP, identical to Hsp70 chaperone) [19], like PDI, is also a multi-domain chaperone. BiP associated with the $\alpha$-subunit of prolyl 4-hydroxylase (P4-H) by a disulfide bond [31]. P4-H consists of two distinct polypeptides, the catalytically more important $\alpha$-subunit and the $\beta$-subunit, which is identical to the multifunctional enzyme, PDI [31]. Thus, BiP associated with the $\alpha$-subunit of P4-H, which is another partner of PDI. The interaction of PDI with its substrates was due to a change in disulfide bonds, indicating that intrachain disulfide bonds between domains and substrates had been reduced [19]. Taken together, these results suggested that vitamin $\mathrm{C}$ oxidizes intracellular-reduced glutathione and affects disulfide bond formation in proteins [30].

Tropomyosin was also identified as a marker of the oxidative effect of vitamin C in NB4 cells. The spot corresponding to tropomyosin was positioned at an isoelectric point (pI) of approximately 5.0 and was attenuated in vitamin C-treated cells. In addition, a new spot having almost the same molecular weight was detected, which was positioned at a pI of 4.9 [19]. This new spot was also identified as tropomyosin, suggesting that post-translational chemical modification had affected its $\mathrm{pI}$ value. This result is consistent with previous data showing that the extracellular signal-regulated kinase (ERK)-mediated phosphorylation of tropomyosin-1 promoted cytoskeleton remodeling in response to oxidative stress [32]. The acidic shift of the spot with pI 5.0 to the phosphorylated tropomyosin spot by treatment with vitamin C was found to be abrogated by co-treatment with PD98059 [19], demonstrating that phosphorylation of tropomyosin was responsible for the observed acidic shift.

The significance of this observation may be related to differences in the regulation of the actomyosin contractile system in non-muscle cells as compared with that present in muscle cells. In addition, proteins that specifically reacted with sera from chronic myeloid leukemia patients included structural proteins, such as $\beta$-tubulin and tropomyosin isoforms [33]. Although the function of these proteins in myeloid leukemia needs further investigation, tropomyosin may have value as a leukemia-associated antigen and as a molecular target in antigen-based immunotherapy. In this regard, it is important to note that vitamin $\mathrm{C}$ causes a tropomyosin isoform to be modified during the immediate early response. 


\section{In Vivo Studies}

Levine et al. reported that reaction products obtained from ascorbate in vitro are also found in vivo [34]. They showed that after i.v. injection, ascorbate baseline concentrations of 50-100 $\mu \mathrm{M}$ in blood and extracellular fluids peaked to $>8 \mathrm{mM}$. After intraperitoneal injection, peaks approached $3 \mathrm{mM}$ in both fluids. They hypothesized that in vivo, ascorbate was a prodrug for selective delivery of ascorbate radical and $\mathrm{H}_{2} \mathrm{O}_{2}$ to the extracellular space. Moreover, a regimen of daily pharmacologic ascorbate treatment significantly decreased growth rates of ovarian $(p<0.005)$, pancreatic $(p<0.05)$ and glioblastoma $(p<0.001)$ tumors established in mice [35]. In addition to inducing oxidative stress, high concentrations of ascorbic acid inhibited cell migration and the gap filling capacity of endothelial progenitor cells (EPCs) [36], and it has been reported that ascorbic acid inhibited corneal neovascularization in a rat model [37].

High concentrations of ascorbic acid also inhibited tumor growth in BALB/C mice implanted with sarcoma 180 cancer cells [38]. The survival rate increased by $20 \%$ in the group that received high doses of ascorbic acid, compared to controls. Gene expression studies from biopsy and wound healing analysis in vivo and in vitro suggested that the carcinostatic effect induced by high doses of ascorbic acid were related to inhibition of angiogenesis [39]. In addition, intraperitoneal administration of high doses of ascorbic acid quantitatively upregulated Raf kinase inhibitory protein (RKIP) and annexin A5 expression in a group of BALB/C mice implanted with S-180 sarcoma cancer cells. The increase in RKIP protein levels suggested that these proteins are involved in the ascorbic acid-mediated suppression of tumor formation [39]. Moreover, high doses of ascorbic acid ( 1 $\mathrm{mM})$ enhanced the apoptosis of cancer cells during co-treatment with paclitaxel, and the combinational treatment of paclitaxel and ascorbic acid ameliorated the side effects caused by paclitaxel in BALB/c mice implanted with or without sarcoma 180 cancer cells [40].

\section{Clinical Studies}

Cases of apparent responses of malignancies to intravenous vitamin $\mathrm{C}$ therapy have been reported, although they were reported without sufficient detail [15,41-46]. A recent study showed that oral administration of the maximum tolerated dose of vitamin $\mathrm{C}$ (18 g/day) produced peak plasma concentrations of only $0.22 \mathrm{mM}$, whereas intravenous administration of the same dose produced plasma concentrations approximately 25 -fold higher. Larger doses (50-100 g) given intravenously resulted in plasma concentrations of approximately $14 \mathrm{mM}$ [41].

Some case reports stated that high dose i.v. vitamin $\mathrm{C}$ has been used by Complementary and Alternate Medicine (CAM) practitioners [47]. Phase I evaluation of intravenous vitamin C in combination with gemcitabine and erlotinib in patients with metastatic pancreatic cancer data did not reveal increased toxicity with the addition of ascorbic acid [48]. No side effects were reported for most patients, while 59 were reported to have lethargy or fatigue out of 11,233 patients that received intravenous vitamin C in 2006 and 8876 in 2008 [47]. Overall, it was reported that high dose intravenous vitamin $\mathrm{C}$ did not appear to cause serious side effects in patients.

Another clinical study reported the depletion of L-ascorbic acid alternating with its supplementation in the treatment of patients with acute myeloid leukemia or myelodysplastic syndromes [49]. During 
the supplementation phase, patients received daily i.v. administration of vitamin C. A pre-therapy in vitro assay was performed for vitamin $\mathrm{C}$ sensitivity of leukemic cells from individual patients. Of the nine patients with the in vitro assay indicating their leukemic cells were sensitive to vitamin $\mathrm{C}$, seven exhibited a clinical response, compared with none of the six patients who were insensitive to vitamin $\mathrm{C}$.

\section{Conclusions}

Previous studies have shown that vitamin $\mathrm{C}$ is involved in the mechanism of action of the intracellular microenvironment (oxidation) state changes that improve therapeutic potential, including apoptosis and necrosis. Although it is difficult to postulate precise vitamin C-specific mechanisms at this time, identification of genes or proteins that are specifically regulated by vitamin $\mathrm{C}$ in certain cellular phenotypes could improve the efficacy of therapies.

\section{Conflicts of Interest}

The author declares no conflicts of interest.

\section{References}

1. Bram, S.; Froussard, P.; Guichard, M.; Jasmin, C.; Auqery, Y.; Sinoussi-Barre, F.; Wray, W. Ascorbic acid preferential toxicity for malignant melanoma cells. Nature 1980, 284, 629-631.

2. Bruchelt, G.; Baader, L.; Reith, A.G.; Holger, N.L.; Gebhardt, S.; Niethammer, D. Rationale for the Use of Ascorbic Acid in Neuroblastoma Therapy. In Human Neuroblastoma; Schwab, M., Ed.; Harwood Academic Publishers: Newark, NJ, USA, 1993; pp. 34-40.

3. Fujinaga, S.; Sakagami, H.; Kuribayashi, N.; Takahashi, H.; Amano, Y.; Sakagami, T.; Takeda, M. Possible role of hydrogen peroxide in apoptosis induction by ascorbic acid in human myelogenous leukemic cell lines. Showa Univ. Med. Sci. 1994, 6, 135-144.

4. De Laurenzi, V.; Melino, G.; Savini, I.; Annicchiarico-Petruzzelli, M.; Finazzi-Agro, A.; Avigliano, L. Cell death by oxidative stress and ascorbic acid regeneration in human neuroectodermal cell lines. Eur. J. Cancer 1995, 31, 463-466.

5. Park, C.H.; Bergsagel, D.E.; McCulloch, E.A. Ascorbic acid: A culture requirement for colony formation by mouse plasmacytoma cells. Science 1971, 174, 720-722.

6. Park, C.H. The biological nature of the effect of ascorbic acids on the growth of human leukemic cells. Cancer Res. 1985, 45, 3969-3973.

7. Park, C.H.; Kimler, B.F.; Bodensteiner, D.; Lynch, S.R.; Hassanein, R.S. In vitro growth modulation by L-ascorbic acid of colony-forming cells from bone marrow of patients with myelodysplastic syndromes. Cancer Res. 1992, 52, 4458-4466.

8. Sakagami, H.; Asano, K.; Fukuchi, K.; Gomi, K.; Ota, H.; Kazama, K.; Tanuma, S.; Kochi, M. Induction of tumor degeneration by sodium benzylideneascorbate. Anticancer Res. 1991, 11, $1533-1538$. 
9. Park, C.H.; Kim, W.S.; Park, C.; Lee, M.H.; Boo, Y.C.; Yoon, S.S. Clinical disease suppression and reduction in acute myeloid leukemia and solid tumors by very high dose of L-ascorbic acid: A new concept and in search of molecular targets. Clin. Cancer Res. 1999, 5, 3784s.

10. Padayatty, S.J.; Sun, H.; Wang, Y.; Riordan, H.D.; Hewitt, S.M.; Katz, A.; Wesley, R.A.; Levine, M. Vitamin C Pharmacokinetics: Implications for Oral and Intravenous Use. Ann. Intern. Med. 2004, 140, 533-537.

11. Levine, M.; Conry-Cantilena, C.; Wang, Y.; Welch, R.W.; Washko, P.W.; Dhariwal, K.R.; Park, J.B.; Lazarev, A.; Graumlich, J.; King, J.; et al. Vitamin C Pharmacokinetics in healthy volunteers: Evidence for a recommended dietary allowance. Proc. Natl. Acad. Sci. USA 1996, 93, 3704-3709.

12. Levine, M.; Wang, Y.; Padayatty, S.J.; Morrow, J.D. A new recommended dietary allowance of vitamin C for healthy young women. Proc. Natl. Acad. Sci. USA 2001, 98, 9842-9846.

13. Chen, Q.; Espey, M.G.; Cherukuri, M.K.; Mitchell, J.B.; Corpe, C.P.; Buettner, G.R.; Shacter, E.; Levine, M. Ascorbic acid at Pharmacologic concentrations selectively kill cancer cells: Ascorbic acid as a pro-drug to deliver hydrogen peroxide to tissues. Proc. Natl. Acad. Sci. USA 2005, 102, 13604-13609.

14. Levine, M.; Rumsey, S.C.; Daruwala, R.C.; Park, J.B.; Wang, Y. Criteria and recommendation for vitamin C intake. J. Am. Med. 1999, 281, 1415-1423.

15. Riordan, N.H.; Riordan, H.D.; Casciari, J.J. Clinicla and experimental experiences with intravenous vitamin C. J. Orthomol. Med. 2000, 15, 201-203.

16. Riordan, H.D.; Hunninghake, R.E.; Riordan, N.H.; Jackson, J.J.; Meng, X.; Taylor, P.; Casciari, J.J.; Gonzalez, M.J.; Miranda-Massari, J.R.; Mora, E.M.; et al. Intravenous Ascorbic Acid: Protocol for its Application and Use. P. R. Health Sci. J. 2003, 22, 287-290.

17. Park, S.; Han, S.S.; Park, C.H.; Hahm, E.R.; Lee, S.J.; Park, H.K.; Lee, S.H.; Kim, W.S.; Jung, C.W.; Park, K.; et al. L-Ascorbic acid induces apoptosis in acute myeloid leukemia cells via hydrogen peroxide-mediated mechanisms. Int. J. Biochem. Cell Biol. 2004, 36, 2180-2195.

18. Park, S. Samsung Medical Center, Seoul, Korea. Unpublished work, 2004.

19. Park, S.; Lee, J.; Yeom, C.H. A proteomic approach to the identification of early molecular targets changed by L-ascorbic acid in NB4 human leukemia cells. J. Cell. Biochem. 2006, 99, 1628-1641.

20. Bienert, G.P.; Schjoerring, J.K.; Jahn, T.P. Membrane transport of hydrogen peroxide. Biochim. Biophys. Acta 2006, 1758, 994-1003.

21. Seaver, L.C.; Imlay, A.J. Hydrogen peroxide fluxes and compartmentalization inside growing Escherichia coli. J. Bacteriol. 2001, 183, 7182-7189.

22. Antunes, F.; Cadenas, E. Estimations of $\mathrm{H}_{2} \mathrm{O}_{2}$ gradients across biomembranes. FEBS Lett. 2000, $475,121-126$.

23. Makino, N.; Sasaki, K.; Hashida, K.; Sakakura, Y. A metabolic model describing the $\mathrm{H}_{2} \mathrm{O}_{2}$ elimination by mammalian cells including $\mathrm{H}_{2} \mathrm{O}_{2}$ permeation through cytoplasmatic and peroxisomal membranes: comparison with experimental data. Biochim. Biophys. Acta 2004, 1673, 149-159.

24. Sousa-Lopes, A.; Antunes, F.; Cyrne, L.; Marinho, H.S. Decreased cellular permeability to $\mathrm{H}_{2} \mathrm{O}_{2}$ protects Saccharomyces cerevisiaein stationary phase against oxidative stress. FEBS Lett. 2004, $578,152-156$. 
25. Mathai, J.C.; Sitaramam, V. Strech sensitivity of transmembrane mobility of hydrogen peroxide through voids in the bilayer. J. Biol. Chem. 1994, 269, 17784-17793.

26. Zhu, X.H.; Shen, Y.L.; Jing, Y.K.; Cai, X.; Jia, P.M.; Huang, Y.; Tang, W.; Shi, G.Y.; Sun, Y.P.; Dai, J.; et al. Apoptosis and Growth Inhibition in Malignant Lymphocytes After Treatment With Arsenic Trioxide at Clinically Achievable Concentrations. J. Natl. Cancer Inst. 1999, 91, 772-778.

27. Dai, J.; Weinberg, R.S.; Waxman, S.; Jing, Y. Malignant cells can be sensitized to undergo growth inhibition and apoptosis by arsenic trioxide through modulation of the glutathione redox system. Blood 1999, 93, 268-277.

28. Noiva, R. Protein disulfide isomerase: The multifunctional redox chaperone of the endoplasmic reticulum. Semin. Cell Dev. Biol. 1999, 10, 481-493.

29. Kemmink, J.; Darby, N.J.; Dijkstra, K.; Nilges, M.; Creighton, T.E. The folding catalyst protein disulfide isomerase is constructed of active and inactive thioredoxin modules. Curr. Biol. 1997, 7 , 239-245.

30. Park, S. Apoptosis of Leukemia Cells Induced by L-Ascorbic Acid and Arsenic Trioxide: The Effect of Oxidative Stress and Glutathione homeostasis.Albina. In Cell Apoptosis and Cancer; Taylor, A.W., Ed.; Nova Science Publishers, Inc.: New York, NY, USA, 2007; pp. 87-111.

31. John, D.C.; Bulleid, N.J. Intracellular dissociation and reassembly of prolyl 4-hydroxylase: The alpha-subunits associated with the immunoglobulin-heavy-chain binding protein (BiP) allowing reassembly with the $\beta$-subunit. Biochem. J. 1996, 317, 659-665.

32. Houle, F.; Rousseau, S.; Morrice, N.; Luc, M.; Mongrain, S.; Turner, C.E.; Tanaka, S.; Moreau, P.; Huot, J. Extracellular signal-regulated kinase mediates phosphorylation of tropomyosin-1 to promote cytoskeleton remodeling in response to oxidative stress: impact on membrane blebbing. Mol. Biol. Cell 2003, 14, 1418-1432.

33. Zou, L.; Wu, Y.; Pei, L.; Zhong, D.; Gen, M.; Zhao, T.; Wu, J.; Ni, B.; Mou, Z.; Han, J.; et al. Identification of leukemia-associated antigens in chronic myeloid leukemia by proteomic analysis. Leuk. Res. 2005, 29, 1387-1391.

34. Chen, Q.; Espey, M.G.; Sun, A.Y.; Lee, J.H.; Krishna, M.C.; Shacter, E.; Choyke, P.L.; Pooput, C.; Kirk, K.L.; Buettner, G.R.; et al. Ascorbate in pharmacologic concentrations selectively generates ascorbate radical and hydrogen peroxide in extracellular fluid in vivo. Proc. Natl. Acad. Sci. USA 2007, 104, 8749-8754.

35. Chen, Q.; Espey, M.G.; Sun, A.Y.; Pooput, C.; Kirk, K.L.; Krishna, M.C.; Khosh, D.B.; Drisko, J.; Levin, M. Pharmacologic doses of ascorbate act as a prooxidant and decrease growth of aggressive tumor xenografts in mice. Proc. Natl. Acad. Sci. USA 2008, 105, 11105-11109.

36. Mikirova, N.A.; Ichim, T.E.; Riordan, N.H. Anti-angiogenic effect ofhigh doses of ascorbic acid. J. Transl. Med. 2008, 6, doi:10.1186/1479-5876-6-50.

37. Peyman, G.A.; Kivilcim, M.; Morales, A.M.; DellaCroce, J.T.; Conway, M.D. Inhibition of corneal angiogenesis by ascorbic acid in the ratmodel. Graefe's Arch. Clin. Exp. Ophthalmol. 2007, 245, 1461-1467.

38. Yeom, C.H.; Lee, G.; Park, J.; Yu, J.; Park, S.; Yi, S.Y.; Lee, H.; Hong, Y.; Yang, J.; Lee, S. High dose concentration administration of ascorbic acid inhibits tumor growth in $\mathrm{BLAB} / \mathrm{C}$ mice implanted with sarcoma 180 cancer cells via the restriction of angiogenesis. J. Transl. Med. 2009, 7, doi:10.1186/1479-5876-7-70. 
39. Park, S.; Ahn, E.S.; Lee, S.; Jung, M.; Park, J.H.; Yi, S.Y.; Yeom, C.H. Proteomicanalysis reveals upregulation of RKIP in S-180 implanted BALB/C mouse after treatment with ascorbic acid. J. Cell. Biochem. 2009, 106, 1136-1145.

40. Park, J.H.; Davis, K.R.; Lee, G.; Jung, M.; Jung, Y.; Park, J.; Yi, S.Y.; Lee, M.A.; Lee, S.; Yeom, C.H.; et al. Ascorbic acid alleviates toxicity of paclitaxel without interfering with the anticancer efficacy in mice. Nutr. Res. 2012, 32, 873-883.

41. Padayatty, S.J.; Riordan, H.D.; Hewitt, S.M.; Katz, A.; Hoffer, L.J.; Levine, M. Intravenously administered vitamin $\mathrm{C}$ as cancer therapy: Three cases. CMAJ 2006, 174, 937-942.

42. Riordan, H.D.; Jackson, J.A.; Riordan, N.H.; Schultz, M. High-dose intravenous vitamin C in the treatment of a patient with renal cell carcinoma of the kidney. J. Orthomol. Med. 1998, 13, 72-73.

43. Riordan, H.D.; Riordan, N.H.; Jackson, J.A.; Casciari, J.J.; Hunninghake, R.; Gonzalez, M.J.; Mora, E.M.; Miranda-Massari, J.R.; Rosario, N.; Rivera, A. Intravenous vitamin C as a chemotherapy agent: a report on clinical cases. P. R. Health Sci. J. 2004, 23, 115-118.

44. Riordan, H.D.; Jackson, J.A.; Schultz, M. Case study: High-dose intravenous vitamin C in the treatment of a patient with adenocarcinoma of the kidney. J. Orthomol. Med. 1990, 5, 5-7.

45. Jackson, J.A.; Riordan, H.D.; Hunninghake, R.E.; Riordan, N. High-dose intravenous vitamin C and long-time survival of a patient with cancer of the head of the pancreas. J. Orthomol. Med. 1995, 10, 87-88.

46. Riordan, N.H.; Jackson, J.A.; Riordan, H.D. Intravenous vitamin C in a terminal cancer patient. J. Orthomol. Med. 1996, 11, 80-82.

47. Padayatty, S.J.; Sun, A.Y.; Chen, Q.; Espey, M.G.; Drislo, J.; Levine, M. Vitamin C: Intravenous use by complementary and alternative medicine practitioners and adverse effects. PLoS One 2010, 5, e11411.

48. Monti, D.A.; Mitchell, E.; Bazzan, A.J.; Littman, S.; Zabrecky, G.; Yeo, C.J.; Pillai, M.V.; Newberg, A.B.; Deshmukh, S.; Levine, M. Phase I evaluation of intravenous ascorbic acid in combination with gemcitabine and erlotinib in patients with metastatic pancreatic cancer. PLoS One 2012, 7, e29794.

49. Park, C.H.; Kimler, B.F.; Yi, S.Y.; Park, S.H.; Kim, K.; Jung, C.W.; Kim, S.H.; Lee, E.R.; Rha, M.; Kim, S.; et al. Depletion of L-ascorbic acid alternating with its supplementation in the treatment of patients with acute myeloid leukemia or myelodysplastic syndromes. Eur. J. Haematol. 2009, $83,108-118$.

(C) 2013 by the authors; licensee MDPI, Basel, Switzerland. This article is an open access article distributed under the terms and conditions of the Creative Commons Attribution license (http://creativecommons.org/licenses/by/3.0/). 